\title{
Prevention of mother-to-child transmission (PMTCT) of HIV: a review of the achievements and challenges in Burkina-Faso
}

This article was published in the following Dove Press journal: HIVIAIDS - Research and Palliative Care

\author{
Laure Stella Ghoma Linguissi ${ }^{1,2}$ \\ Tani Sagna ${ }^{3,4}$ \\ Serge Théophile Soubeiga ${ }^{1,4}$ \\ Luc Christian Gwom ${ }^{5}$ \\ Céline Nguefeu Nkenfou ${ }^{6,5}$ \\ Dorcas Obiri-Yeboah ${ }^{7}$ \\ Abdoul Karim Ouattara ${ }^{\mathrm{I}, 4}$ \\ Virginio Pietra ${ }^{4}$ \\ Jacques Simpore ${ }^{1,4}$
}

'Laboratoire de Biologie Moléculaire et de Génétique, Université Ouaga I Pr Joseph Ki-Zerbo, Ouagadougou, Burkina Faso; ${ }^{2}$ Institut National de Recherche en Sciences de la Santé (IRSSA), Brazzaville, Republic of Congo; ${ }^{3}$ Institut de Recherche en Sciences de la Santé (IRSS), Ouagadougou, Burkina Faso; ${ }^{4}$ Centre de Recherche Biomoleculaire Pietro Annigoni (CERBA), Ouagadougou,

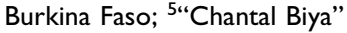
International Reference Centre for Research on HIV/Aids Prevention and Management (CBIRC), Yaoundé, Cameroon; 'Higher Teachers' Training College, University of Yaoundé I, Yaoundé, Cameroon; ${ }^{7}$ Department of Microbiology and Immunology, School of Medical Sciences, University of Cape Coast, Cape Coast, Ghana

Correspondence: Jacques Simpore Centre de Recherche Biomoléculaire Pietro Annigoni, Laboratoire de Biologie Moléculaire et de Génétique (CERBA/ LABIOGENE), UFR/SVT, Université

Ouaga I Pr Joseph Ki-Zerbo, OI BP 364

Ouagadougou 01, Burkina Faso

$\mathrm{Tel}+22650307064 / 65$

Fax +22650307242

Email jacques.simpore@labiogene.org
Background: Burkina-Faso's HIV/AIDS program is one of the most successful in Africa, with a declining HIV prevalence and treatment outcomes that rival those of developed countries. Prevention of mother-to-child transmission (PMTCT) guidelines in BurkinaFaso, initiated in the year 2000, were revised in 2004, 2006 and 2010. The guideline document has since undergone several stages of improvement, largely based on recommendations from WHO, with adaptations by local experts in the field. Option B + adopted since August 2014 in Burkina-Faso has enabled maintenance of mothers on longer treatment and increasing their survival and that of their children. Through this review, we describe the achievements and challenges of HIV PMTCT programs in Burkina-Faso.

Aims of study: This study had the following objectives: 1) describing the historical perspective of PMTCT implementation in Burkina-Faso; 2) presenting the effectiveness of interventions at improving PMTCT service delivery and promoting retention of mothers and babies in care; and 3) determining the impact of male partner involvement on PMTCT in Burkina-Faso.

Methodology: A literature search was conducted in PubMed and Google. Search terms included the following keywords: "HIV testing"; "prevention"; "mother"; "child"; "male partner"; "counseling"; "involvement"; "participation"; and the grouped terms "PMTCT and partners"; "VCT"; "barriers and/or factors"; "Male involvement in PMTCT"; and "BurkinaFaso". Data collection took place from May to October 2015. The search was limited to articles published between January 2002 and December 2015. UNICEF and UNAIDS web sites were also used to find relevant abstracts and documents.

Results: Studies have revealed that with PMTCT, HIV transmission rate moved from $10.4 \%$ in 2006 to $0 \%$ in 2015. The PMTCT program remains the best way to care for HIV-infected pregnant women and their babies. The current PMTCT policy is based on evidence that male partner involvement is associated with women's completion of PMTCT.

Conclusion: This study shows that the reduction in mother to child transmission of HIV in Burkina-Faso over the years is mainly due to the improvement of PMTCT programs. Efforts still need to be made about the involvement of male partners.

Keywords: HIV/AIDS, PTMTCT, HAART, Burkina Faso

\section{Introduction}

Mother-to-child transmission of HIV (MTCT) is defined as the transmission of HIV from a mother to her child during pregnancy, labor, delivery or during breastfeeding. In the absence of any interventions, transmission rates range from $15 \%$ to $45 \%$. Without HAART, half of the children born with HIV die by the age of two years, 
and 80 percent die by the age of five years. Globally, 2.6 million children younger than 15 years of age are living with HIV, yet only $32 \%$ are accessing HAART. Despite significant efforts and achievements in prevention of mother-to-child transmission (PMTCT) over the past decade, approximately 240,000 children worldwide became newly infected with HIV in 2013.

The "90-90-90" targets aim to have $90 \%$ of all children living with HIV diagnosed, $90 \%$ of those diagnosed HIVpositive receiving treatment and $90 \%$ of those children receiving treatment achieving viral suppression by 2020 . Sub-Saharan Africa accounts for almost $70 \%$ of the global total of new HIV infections. ${ }^{1}$ The AIDS prevalence rate in Burkina Faso, in the space of 30 years (between 1986 and 2016), decreased from $7 \%$ to $0.90 \%$. In 2014 , an estimated 95,000 people in Burkina-Faso were living with HIV, and the number of women aged 15 years and over living with HIV was 53,000.

The research projects implemented have led to feasible and effective interventions to reduce the risk of mother-to-child transmission of HIV. In Burkina-Faso, PMTCT programs remain a priority in the national strategic frameworks. Different experiments have shown the inadequacy of monotherapy with Nevirapine for the purpose of PMTCT. The prevention of mother-to-child transmission of HIV has involved the use of HAART which allows for the significant reduction of MTCT. Improving access to care for the motherbaby pair also requires interventions such as HIV testing, therapeutic management and infant feeding policies. HIV counseling and testing plays a major role in that care is extended not only to the child but also to the partner of the infected pregnant woman. Early detection by testing for viral antigen in infants born to infected mothers as early as 6 weeks of life significantly improves follow-up of infected children. ${ }^{2}$

Efforts are being made to facilitate the monitoring of women and newborns during prenatal and postpartum consultations. Achieving program targets requires improvement and availability of services, and mobilization of beneficiaries to use them.

\section{Aim of study}

This review therefore had the following objectives: 1) Describing the historical perspective of PMTCT implementation in Burkina-Faso; 2) Presenting the effectiveness of interventions at improving PMTCT service delivery and promoting retention of mothers and babies in care; 3) Determining the impact of male partner involvement on PMTCT in Burkina-Faso.

\section{Methods}

Literature search was conducted in PubMed and google. We systematically searched for articles written in both English and French. The search was limited to articles published between January 2002 and December 2015.

Data collection took place from May to December 2015. Burkina-Faso developed and adopted the first PMTCT program between 2001 and 2005, which was implemented in 2002. Effort was made to retrieve all published articles related to PMTCT in Burkina-Faso within this period. Search terms consisted of the following key words: "HIV testing"; "prevention"; "mother"; "child"; "male partner"; "counseling"; "involvement"; "participation", and the grouped terms "PMTCT and partners"; "VCT and acceptability in PMTCT"; "barriers and/or factors"; "Male involvement in PMTCT"; and "Burkina-Faso". Articles were then manually selected. Other documents not indexed by PubMed also served as references for this work: WHO, UNICEF, UNAIDS reports, UNGASS Report and Burkinabe health institutions (SEP/CNLS) internal reports. All search results were subsequently downloaded by two of the authors into an electronic register using Zotero.

\section{Area of study}

PMTCT programs were introduced in three major cities: Ouagadougou, Bobo-Dioulasso and Ouahigouya in 2003 and just over a decade later, this program has been rolled out over the 63 health districts in BurkinaFaso.

\section{Inclusion and exclusion criteria Study participants}

Studies conducted among women and children were eligible for inclusion.

\section{Types of studies}

All study designs were eligible for inclusion.

\section{Type of outcomes}

A range of outcomes were relevant including views, experiences and attitudes of HIV testing, counseling or treatment among mothers or children, the statement of the effectiveness of the PMTCT program confirmed by the availability of the proportion of infected children under and/or out of this program. Studies that examined broader experiences of PMTCT associated with partners were also eligible for inclusion. 


\section{Study selection}

A group of authors chose articles, using keywords, based on titles and abstracts. Two authors independently screened all titles and abstracts retrieved from the database searches according to the inclusion and exclusion criteria described. Another group of authors reviewed the full text and summarized the key result for final inclusion. Topics of relevance were about: HIV infection, characteristics of the population (eg, mother, child, male partners) and the topics such as PMTCT, breastfeeding, HAART, Prophylaxis, HIV testing, Counseling, prevention and acceptability of HIV testing.

\section{Methods of analysis/synthesis}

Studies typically examined the PMTCT experiences of women (Mother-baby pair, HIV testing and Counseling, HAART, prophylaxis, etc.). By examining the findings of each included study, descriptive themes were independently coded. Once all the included studies had been examined and coded, the resulting themes and sub-themes were discussed to examine their relationship to the research questions. We synthesized the data by summarizing the key results of each study. The qualitative synthesis then proceeded by using these "descriptive themes" to develop "analytical themes", which were interpreted by the review team of authors considering the overarching research questions. We then listed all relevant targeted topics of relevance identified in the individual studies as well as relevant study information: WHO scheme, location, biological analysis, mutation profile and year of publication. The effectiveness of PMTCT was described by examining published data on the rate of mother-to-child HIV transmission from 2002 to 2015 .

\section{Results}

\section{Results of study selection}

A total of 208 references were identified from online literature search. Based on title and abstract screening, 134 references were identified as potentially relevant. In the last round of full-text screening, from the 60 relevant papers, the focus was to identify studies that examined perspectives on, or experiences of, PMTCT. There were many articles excluded in this review: 74 duplicated studies identified as potentially relevant, 34 studies found as unrelated articles, 10 articles on Burkina-Faso or articles on women in Burkina-Faso. 19 studies found to be HIV and 11 studies found to be PMTCT. The process of study selection is summarized in Figure 1.

\section{Search flow chart}

Eighty-three publications were identified. After the first and second rounds of screening of the 83 publications based on the titles and abstracts, 40 studies were preselected for the final screening using the full text. At the end of assessment, this selection was enriched by $7 \mathrm{WHO}$, UNAIDS or UNICEF reports. Details related to the search workflow are represented in the flow diagram (Figure 1).

\section{Rates of mother-to-child transmission of HIV}

Between May 2002 and January 2003, of the 2,464 women receiving prenatal counseling, 22.2\% (546 women) had accepted pre-test counseling. On the other hand, almost all the women who participated in counseling were determined to test and know the outcome. This efficacy could be attributed to the use of rapid tests to perform pre- and post-test at one sitting with results being available to the women in 15-20 mins. Many studies showed that the rate of vertical transmission of HIV-1 was $0.0 \%$ in children whose HIV-infected mothers were receiving triple therapy with a combination of Zidovudine, Lamivudine and Nevirapine (AZT/3TC/NVP) or were on a prophylactic AZT/3TC treatment. ${ }^{3-8}$ MTCT rate was found significantly higher in mothers taking only Nevirapine (22/41) compared to those taking HAART $(2 / 172) .{ }^{10}$ In this study, MTCT of HIV infection was strongly related to the treatment status of the child. Similarly, the proportion of children infected through breastfeeding and whose mothers were not on HAART was significantly higher $(23 / 23)$ than those born to HAART experienced mothers $(0 / 139) .{ }^{9}$

Initially, studies showed that when mothers had received only the mono-prophylaxis of Nevirapine, residual transmission risk was $9.09 \%,{ }^{10} 10.4 \%{ }^{7}$ (Table 1). For the triple prophylaxis AZT +3TC + NVP HIV transmission was rated at $4.55 \%$ and $1.75 \%,{ }^{10,11} 6.8 \%{ }^{4}$ The HAART protocol showed a vertical transmission rate of $0.00 \%{ }^{4-6,8,11}$ Concerning HAART, Nucleosidic and Non Nucleosidic Reverse transcriptase (RT) inhibitors (NRTI and NNRTI) are commonly used in the context of PMTCT in BurkinaFaso. NRTIs and NNRTIs efficacies are diminished by substitutions occurring at positions $\mathrm{M} 184 \mathrm{~V}$ and $\mathrm{K} 103 \mathrm{~N}$, respectively. ${ }^{11,12}$ Such mutations generally emerge from exposure to first-line ART regimens used in the PMTCT nationwide. It was shown that, in addition to resistance mutations found in the reverse transcriptase [RT] (Y18CY), protease-associated mutations such as V8IV can mitigate the 


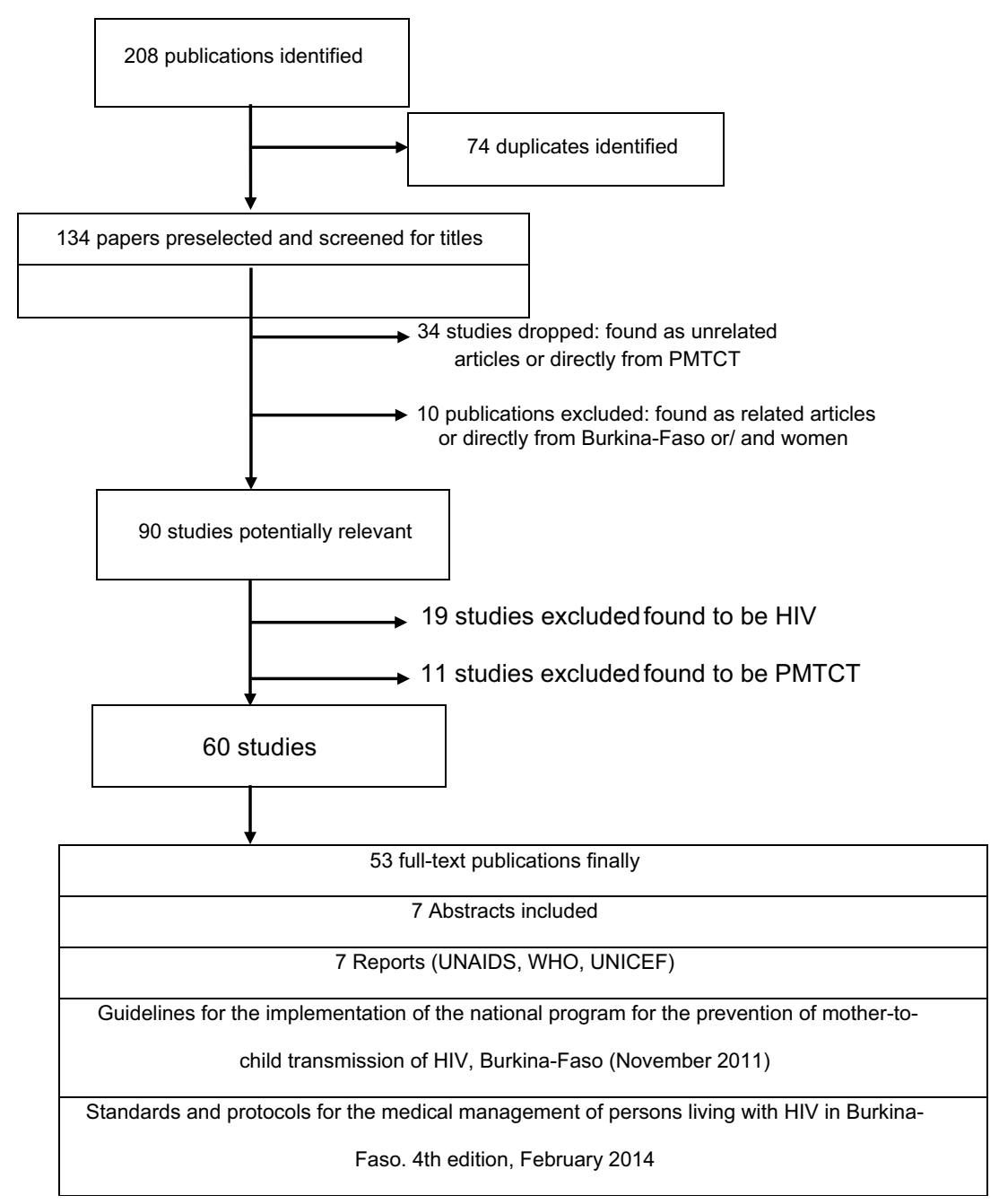

Figure I Search flow diagram search.

efficacy of protease inhibitors (PI) in the same context. ${ }^{7}$ Altogether, we can consider that, in Burkina Faso, the rate of mother-to-child transmission of HIV moved from 10.4\% in 2006 to $0.0 \%$ in 2015 , thus reflecting the effectiveness of the PMTCT. It is noteworthy that there have been many changes in programs to reduce the risk of transmission.

\section{Initiation of PMTCT of HIV program in Burkina Faso}

The PMTCT program began as a pilot project in BurkinaFaso in 2002 carried out at the Saint Camille Medical Center, an epidemiological surveillance site chosen to initiate the experiment. Among the positive screened women, the majority had accessed the different stages of PMTCT (during pregnancy, childbirth, postpartum and breastfeeding). The introduction of PMTCT activities in Saint Camille then raised the possibility of extending the experience of the Saint Camille Medical Center, hence its reproducibility in other national sites. ${ }^{15}$

PMTCT guidelines, in Burkina-Faso, initiated in 2000 were revised in 2004, 2006 and 2010. The guideline has since undergone several stages of improvement, largely based on recommendations from the WHO, with adaptations by local experts in the field. The results of the study of Ouedraogo et al recommended for Burkina Faso, the abandonment of Option $\mathrm{A}$ and the adoption of option $\mathrm{B}+{ }^{16}$ One study in Burkina Faso focused on a model for specific counseling that should provide mothers with general information, and personalized support that they need in order to receive and manage disclosure of their child's HIV status. ${ }^{17}$

\section{Regimens and policy}

Numerous studies in Burkina-Faso have shown the effectiveness of lifelong HAART regimens for the prevention 


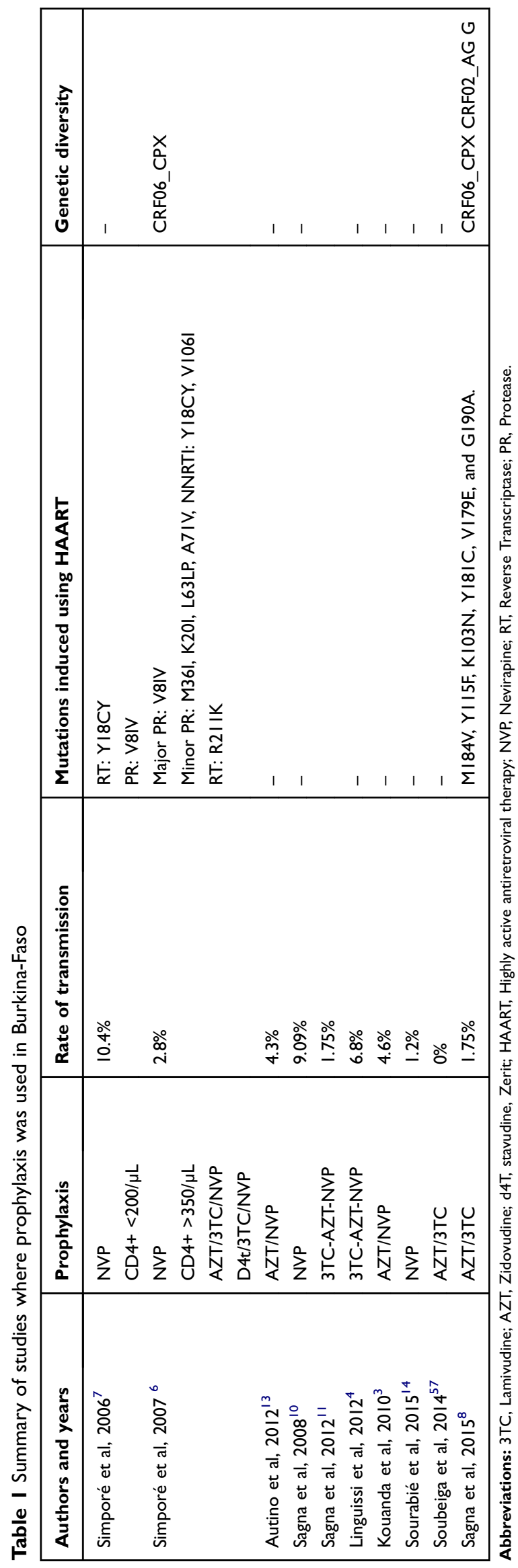

of mother-to-child HIV transmission. ${ }^{4,5,8,18}$ Regarding the ARV prophylaxis for PMTCT, protocols adopted in Burkina-Faso for 2001-2005 were based on Nevirapine monotherapy.

The main treatment was the single-dose Nevirapine for women during labor and a single dose of Nevirapine to infants within $72 \mathrm{hrs}$ after birth. ${ }^{19,20}$ After that, there was the zidovudine (AZT) prophylactic scheme from the 36 weeks of gestation available. ${ }^{21}$

In 2012, Burkina-Faso implemented a new policy (Option $\mathrm{B}+$ ) to provide all HIV-infected pregnant and breastfeeding women with lifelong antiretroviral therapy (ART) regardless of CD4 count. ${ }^{22}$ Breast-feeding was also initially discouraged as it was another route of postpartum transmission of HIV. Option B+ was an important innovation that could accelerate progress in Burkina-Faso and other countries toward the goal of eliminating mother-tochild transmission of HIV worldwide. ${ }^{22}$ Burkina-Faso has then reached a point where almost complete eradication of pediatric HIV is a reality with $0.0 \%$ of HIV transmission from mother to child when mothers infected with HIV were on HAART with regard to the sites studied. ${ }^{4-8,18}$ Practically, HIV-positive women receive highly effective treatment as soon as they enter the program at any clinic throughout the country. "Protected" breast-feeding is now promoted as infant feeding option and with support in prevention of HIV transmission while babies will benefit from the known nutritional and immunological properties of breast milk. ${ }^{23}$ Additionally, counseling on safe infant feeding practices is provided to all new mothers. ${ }^{7,24}$ At six weeks of age, these children were monitored for HIV infection status through blood sampling for HIV molecular testing. So, there have been several improvements in the national PMTCT protocol ever since according to the World Health Organization (WHO) updated guidelines, but it will also be necessary to survey the accessibility of PMTCT services by women from areas that do not offer this service..$^{25,26}$

\section{Discussion}

\section{Elimination of mother to child transmission: a reality in Burkina-Faso}

The elimination of mother-to-child transmission of HIV is now a reality in Burkina-Faso. PMTCT program was first implemented in May 2002 at Saint Camille Medical Center, a big mother-and-child health care facility in Ouagadougou, visited by more than 7,000 babies each year (Centre Médical Saint Camille, 2004). Management 
of mothers and children is improving in Burkina-Faso due to better treatment guidelines and to the availability of real-time PCR (rtPCR) for viral load quantification and availability of CD4 $\mathrm{T}$ cells measurement.

\section{Progress in preventing mother-to-child transmission}

The early management of pregnant women include the HIV diagnosis in the first trimester of pregnancy and ARV treatment of choice as soon as test is positive. ${ }^{27}$ It recommended to repeat HIV testing in the third trimester of pregnancy when the first test was negative to identify seroconversions during pregnancy. ${ }^{28}$ There have been progressively efficient interventions to prevent MTCT of HIV in sub-Saharan Africa. ${ }^{29,30}$ Most Sub-Saharan African countries first used a less efficient system consisting of single dose of Nevirapine (NVP) for PMTCT, ${ }^{31-33}$ compared to western countries, which have long used triple therapy. ${ }^{34-36}$ In Burkina-Faso, likewise, there is also progress in effective interventions to prevent MTCT of HIV. ${ }^{37-39}$ In this country, many interventions were first based on single-dose ART that was implemented to reduce the MTCT of HIV ${ }^{3,6,7}$ or single-dose zidovudine. ${ }^{16,20,40}$ This HIV therapeutic approach was used in clinical trial as well as in routine care of HIV-infected pregnant women. ${ }^{33,41,42}$ In BurkinaFaso, ART has been shown to impact MTCT by reducing HIV maternal viral load, ${ }^{6,10}$ by providing effective preexposure prophylaxis to babies and by functioning as post-exposure prophylaxis for newborns. ${ }^{43-45}$

The Kesho Bora trial was conducted between 2005 and 2008 with over 800 women in Burkina-Faso, Kenya and South Africa, to compare the efficacy of the different protocols including combined Zidovudine, Lamivudine and Lopinavir/ritonavir with that of prophylactic Zidovudine during pregnancy, followed by a single dose of Nevirapine. A combination of three antiretrovirals: Zidovudine, Lamivudine and Lopinavir/ritonavir were administered to a group of pregnant women between the 28th and the 36th week and until the sixth month of breastfeeding. Only $5.4 \%$ of children at age 12 months were infected, against $9.5 \%$ in the group that followed a standard prophylaxis. This new combination was revealed to be even more effective in women whose viral load was high. The Kesho Bora trial showed that the triple antiretroviral prophylaxis during pregnancy and breastfeeding is safe and reduces the risk of HIV transmission to infants. ${ }^{39,46,47}$ A recent study conducted in the framework of this project revealed that, even with maternal triple-ARV prophylaxis during breastfeeding, early weaning remains associated with lower HIV-free survival, driven by increased mortality. ${ }^{48}$

\section{Evolution of guidelines in Burkina-Faso from 2002 to 2015}

In 2006, Burkina-Faso revised its PMTCT guidelines and introduced the use of the most effective ARV: ART was available to eligible women according to their immunological status and initiated exclusive breastfeeding for 3-6 months for HIV-positive women. ${ }^{49}$ The protocol provided the use of prophylaxis in women not eligible for HAART. Since 2006, Burkina-Faso introduced the use of Zidovudine (AZT) $300 \mathrm{mg} /$ lamivudine (3TC) $150 \mathrm{mg}$ twice daily from 32 weeks gestation, during labor by single dose of Nevirapine $(200 \mathrm{mg})$ at onset of labor. ${ }^{50}$ Women continued with Zidovudine (AZT) $300 \mathrm{mg} / \mathrm{lami}-$ vudine (3TC) $150 \mathrm{mg}$ twice daily for a week after birth ${ }^{50}$ and the baby received a single dose of Nevirapine within $72 \mathrm{hrs}$ and Zidovudine twice a day for one week. ${ }^{21} \mathrm{~A}$ study carried out in Burkina-Faso on a survey of the knowledge of women about HIV and breastfeeding showed that there was an association very significant between acceptability of HIV screening and willingness to breastfeed. ${ }^{51}$ Saker et al observed an overall acceptability of HIV testing after voluntary individual counseling of $73 \%$ in the Nouna District in a rural area. ${ }^{52}$

With the guidelines implemented in 2010, the national option was option A, this option will be used until 2013, followed by the implementation of option B from 2014. The WHO PMTCT Protocol in Option A has reduced the vertical transmission of HIV and to preserve breast-feeding. ${ }^{53}$

In an ongoing PMTCT option $\mathrm{B}+$ era, it would be relevant to assess the performance of the PMTCT program to shed light on what could potentially be the implementation challenges for new WHO PTMCT antiretroviral guidelines. The WHO 2013 guidelines recommend initiation of ART for all pregnant and lactating women living with HIV. $^{54}$

\section{Current protocol in use in Burkina-Faso}

One of the reasons for implementing the new WHO guidelines for PMTCT was to choose between option B or B+ as a result of the difficulties encountered in the implementation of option A. The ART regimen for $\mathrm{B}+$ option for HIV1+ pregnant women was: $\mathrm{TDF} / \mathrm{FTC} / \mathrm{EFV}$ or $\mathrm{TDF} / \mathrm{FTC}+$ $\mathrm{EFV}$ or $\mathrm{TDF} / 3 \mathrm{TC}+\mathrm{EFV}$ (with Lpv/rtv replacing EFV in case of co-infection with HIV2 or HIV2 alone). The choice of TDF, more expensive, instead of AZT is justified 
by the side effects of AZT (anemia, leucopenia) which are relatively frequent and difficult to diagnose and manage at the peripheral level, and, by the fact that TDF can be administered once daily, like $3 \mathrm{TC}$ and EFV. ${ }^{55}$ The treatment and prophylactic regimens in Burkina-Faso according to the 2014 guidelines are shown in Tables 2 and 3. The new protocol introduced in Burkina-Faso since January 2014 is the recommended triple therapy from the 14th week of pregnancy with the preferred regimen: [AZT/ 3TC+EFV] (Table 3). And if the pregnant women are HIV-2 mono-infected or mixed-infected (HIV-1 and HIV2) they received: $[\mathrm{AZT}+3 \mathrm{TC}+\mathrm{ABC}]($ Table 3$)$. The newborn is treated with NVP or AZT for 6 weeks. ${ }^{56}$ No data are available at national level to assess the effectiveness of this new protocol. However, in the study by Soubeiga et al (2015), for 160 HIV-positive pregnant women followed on this protocol, no child was being infected with HIV after six weeks of birth. This protocol for PMTCT is proven effective and significantly reduced the risk of transmission of HIV-1 from mother to child, but there is still a need to have a large number of women for confirmation. $^{8,57}$

\section{Resistance to ARV, subtypes of HIV-I and their transmission from mother to child}

Recent studies investigating variations between HIV subtypes and rates of mother-to-child transmission ${ }^{58,59}$ revealed that certain HIV subtypes/CRFs are predominantly associated with specific modes of transmission. ${ }^{60-62}$ Recently in Burkina-Faso, Sagna et al observed that CRF06_CPX (58.8\%), CRF02_AG (35.3\%) and subtype G (5.9\%) were predominantly present in HIV-positive mothers and these subtypes could be detected in each child from mother-child pairs (M44/E44: CRF06_CPX; M102/E102: CRF02_AG). ${ }^{11}$ Furthermore, several studies on mother-to-child pairs reported low reversion rates of transmitted mutations. ${ }^{63,64}$ This brings to the fore the transmission of resistant strains from mother to child and thus care should be taken when choosing the treatment molecules for this child. ${ }^{5}$

\section{Role of males' partners in PMTCT}

Many sub-Saharan countries adopted male partner involvement in PMTCT program with the aim to increase the uptake of PMTCT services. ${ }^{65-69}$ Over 15 countries participated in the project Engender Health, including Burkina-Faso. This project used an approach called "Men As Partners", in order to improve the health of the whole family. ${ }^{70}$ The involvement of the partner to provide care during the pregnancy is also encouraged as well as HIV testing for this partner. ${ }^{71,72}$ Among the achievements of this approach was the strengthening capacity of the centers to engage male partners in HIV prevention services, including HIV testing and PMTCT (71,72). Case studies in Uganda, Kenya, Zambia, Zimbabwe and Ethiopia showed the low rate of male partner participation in the PMTCT activities and in antenatal Voluntary Counseling and Testing with their spouses. ${ }^{72,73}$ However, other studies have reported success with a "facilitated disclosure approach". ${ }^{74,75}$ However, PMTCT programs in Africa still find it difficult to reach male partners of women in antenatal care (ANC), ${ }^{65,69,76,77}$ as reported in the study done in Burkina Faso. ${ }^{78}$

Partners with comprehensive knowledge on HIV/AIDS were more likely to be involved in the PMTCT program than those who do not have comprehensive knowledge on HIV/ AIDS. ${ }^{75}$ Sarker et al (2007) also attributed low uptake of PMTCT and failure of women to return for their HIV results in poor partners support. ${ }^{52}$ Studies in Burkina-Faso recommended that women should engage in discussions about testing with their partners. ${ }^{78,79}$ Dropout among those who have discussed HIV testing with their partners was found to be low in Burkina-Faso. ${ }^{52,80,81}$ In Malawi, a study revealed that male partner involvement increases the uptake of some PMTCT interventions by HIV-positive women. ${ }^{66}$ Male partners need to be considered and treated as constitutive part of reproductive health ${ }^{82}$ and can no longer be excluded from any debate surrounding issues like pregnancy or HIV/ AIDS. ${ }^{83}$ Couple-oriented post-test HIV counseling delivered to pregnant women is an innovative intervention, ${ }^{38,84-87}$ which shows that it is possible to bring men to prenatal

Table 2 Therapeutic regimens for seropositive pregnant women in need of ART and infants born to ART mothers, in Burkina Faso

\begin{tabular}{|l|l|}
\hline For the Mother & For beast-fed or non-breast-fed infants \\
\hline $\begin{array}{l}\text { Ist intention: } \mathrm{AZT}+3 \mathrm{TC}+\mathrm{NVP} \\
\text { 2nd intention: } \mathrm{AZT}+3 \mathrm{TC}+\mathrm{EFV} \text { or TDF+3TC (or FTC) +NVP or TDF+3TC (or FTC) +EFV }\end{array}$ & $\begin{array}{l}\text { Ist intention: NVP every day } 4 \mathrm{mg} / \mathrm{kg} \text { single dose } \\
\text { 2nd intention: AZT every day } 4 \mathrm{mg} / \mathrm{kg} \times 2 \mathrm{times} / \mathrm{day} \\
\text { Duration: from birth to } 6 \text { weeks }\end{array}$ \\
\hline
\end{tabular}

Abbreviations: 3TC, Lamivudine; AZT, Zidovudine; ART, Antiretroviral therapy; NVP, Nevirapine; EFV, Efavirenz; TDF, Tenofovir; FTC, Emtricitabine. 


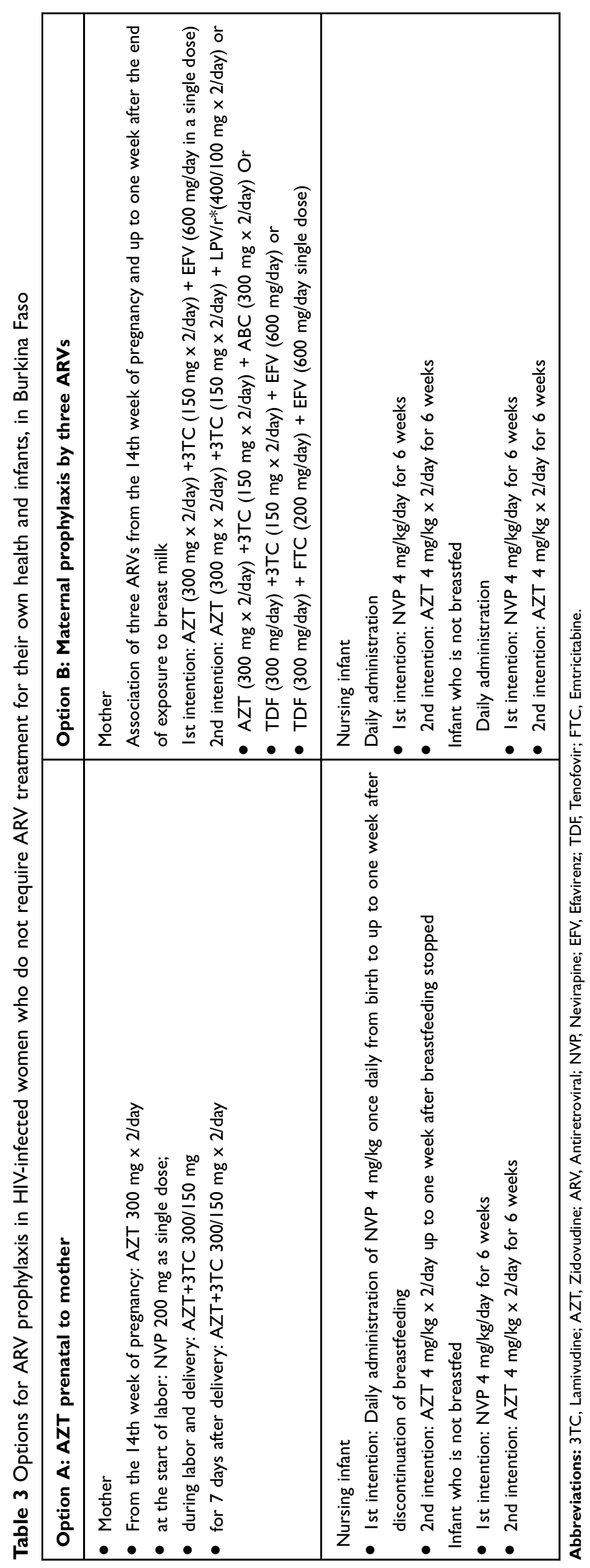


HIV testing through the involvement of their pregnant partner. $^{38,84,85}$ Burkina-Faso PMTCT current policy is based on evidence that male partner involvement is associated with women's completion of PMTCT in sub-Saharan Africa. $^{33,88-90}$

\section{Challenges faced of PMTCT strategies in Burkina-Faso}

Challenges arise in achieving successful PMTCT in BurkinaFaso. ${ }^{91}$ Two major challenges have emerged in previous studies: adhesion of pregnant women during the voluntary counseling; acceptability to screening tests for all pregnant women and loss to follow-up among women. ${ }^{6,24,52,78}$ Sarker et al have shown that the quality of pre-test counseling was very poor as $42 \%$ did not understand the process. The absence of doctors and mismanagement of time for posttest counseling were the main reasons why women did not receive test results. ${ }^{52}$ This challenge of adhesion also appears during ART for HIV-positive pregnant women and for their newborns. ${ }^{6}$ Another dilemma is that of autonomy for breastfeeding. ${ }^{6}$ Finally, the risk of causing resistance to ARV in children affected by their mothers is important. ${ }^{5}$ Studies have shown antiretroviral resistance among HIV-positive mothers and children. ${ }^{5,6,12}$

PMTCT programs are beneficial in Burkina Faso because they can also serve as an example for other prevention programs, especially since the government announced in September 2018 a new therapeutic option for all people infected with HIV for treatment regardless of their clinical or viro-immunological level.

\section{Recommendations}

HAART significantly reduces vertical transmission of HIV1. However, the consequence of HAART is the appearance of mutations that induce resistance of HIV to ART and thus limits the available choice of best drug combination. It is imperative to establish a permanent interaction between researchers, physicians and pharmacists for better care of mothers and their children. There should be strengthening of a network of monitoring and surveillance of drug resistance in Burkina-Faso. In order to maintain the reduction of mother-to-child transmission of HIV in Burkina Faso, it is of great importance that all HIV-positive pregnant women follow the PMTCT protocol and that PMTCT programs reach male partners of women in antenatal care. The coverage of the PMTCT protocol in Africa and more specifically in Burkina-Faso should be increased.

\section{Conclusions}

PMTCT programs focus not only on pregnant women well-being, but also on the protection of newborns against HIV infection. This review demonstrates that effective approaches and techniques are deployed for reducing the HIV transmission risk in the mother-baby pair although there is the need to improve PMTCT strategy perhaps by promoting retention of mothers and babies in care, by involving male partners.

\section{Abbreviations list}

AIDS, acquired immunodeficiency syndrome; ANC, antenatal care; ART, antiretroviral therapy; ARV, antiretroviral; AZT, Zidovudine; CNLS, Conseil National de Lutte contre le SIDA; EFV, Efavirenz; HAART, highly active antiretroviral therapy; HIV, human immunodeficiency virus; MTCT, mother-to-child transmission; NNRTI, non-nucleosidereverse-transcriptase inhibitors; NPV, Nevirapine; NRTI, nucleoside reverse transcriptase inhibitors; PCR, polymerase chain reaction; PI, protease inhibitor; PMTCT, prevention of mother-to-child transmission; RT, reverse transcriptase; rtPCR, real-time PCR; SEP/CNLS, Secrétariat Exécutif Permanent du Conseil National de Lutte contre le SIDA; TDF, Tenofovir; UNAIDS, United Nations Program on HIV/AIDS; UNGASS, United Nations General Assembly Special Session; UNICEF, United Nations International Children's Emergency Fund; VCT, voluntary counselling and testing; WHO, World Health Organization.

\section{Availability of data and material}

The datasets used and/or analyzed during the current study are available from the corresponding author on reasonable request.

\section{Acknowledgment}

The authors gratefully acknowledge the support of Montari Soumou Arsinel Diorfis for proofreading the manuscript.

\section{Author contributions}

All authors contributed towards data analysis, drafting and critically revising the paper, gave final approval of the version to be published, and agreed to be accountable for all aspects of the work.

\section{Disclosure}

The authors report no conflicts of interest in this work. 


\section{References}

1. UNAIDS. F A C T S H E E T 2014 [Internet]. Geneva, Switzerland: UNAIDS; 2014:6. Available from: http://files.unaids.org/en/media/unaids/ contentassets/documents/factsheet/2014/20140716_FactSheet_en.pdf. Accessed November 4, 2018.

2. UNGASS. UNGASS. Rapport sur le Burkina Faso: suivi de la déclaration d'engagement sur le VIH/SIDA. 2010 [Internet]. Burkina-Faso; 2010:40. Available from: http://www.unaids.org/en/dataanalysis/. Accessed November 4, 2018.

3. Kouanda S, Tougri H, Cissé M, et al. Impact of maternal HAART on the prevention of mother-to-child transmission of HIV: results of an 18-month follow-up study in Ouagadougou, Burkina Faso. AIDS Care. 2010;22:843-850. doi:10.1080/09540120903499204

4. Linguissi LSG, Bisseye C, Sagna T, et al. Efficiency of HAART in the prevention of mother to children HIV-1 transmission at Saint Camille medical centre in Burkina Faso, West Africa. Asian Pac J Trop Med. 2012;5:991-994. doi:10.1016/S1995-7645(12)60037-6

5. Sagna T, Bisseye C, Tegewende CR, et al. Prevention of mother-to-child HIV-1 transmission in Burkina Faso: evaluation of vertical transmission by PCR, molecular characterization of subtypes and determination of antiretroviral drugs resistance. Glob Health Action. 2015;8:26065.

6. Simpore J, Pietra V, Pignatelli S, et al. Effective program against mother-tochild transmission of HIV at Saint Camille Medical Centre in Burkina Faso. J Med Virol. 2007;79:873-879. doi:10.1002/jmv.20840

7. Simpore J, Pietra V, Savadogo A, et al. Reduction of mother-to-child transmission of HIV at Saint Camille Medical Centre in Burkina Faso. J Med Virol. 2006;78:148-152. doi:10.1002/jmv.20521

8. Soubeiga ST, Compaoré R, Djigma F, et al. Evaluation du traitement antirétroviral chez les femmes enceintes VIH-1 positif, sur la transmission de l'infection de la mère à l'enfant : cas du Centre Médical Saint Camille de Ouagadougou, au Burkina Faso. Pan Afr Med J. 2015;20. doi:10.11604/pamj.2015.20.399.5627.

9. Sourabie Y, Ouedraogo SM, Bazie WW, et al. Impact of art mother and child on the HIV status of the child born to HIV-positive mothers in Burkina Faso: towards the adoption of an effective Pmtct policy. $J$ Hematol Thromboembolic Dis. 2015;03. [cited 2017 Apr 22]. Available from: http://www.esciencecentral.org/journals/impact-ofart-mother-and-child-on-the-hiv-status-of-the-child-born-to-hivpositi vemothers-in-burkina-faso-towards-the-adoption-of-an-effectivepmtctpolicy-2329-8790-1000198.php?aid=47704.

10. Sagna T, Bisseye C, Sanou DS, et al. Diagnostic précoce, par RT/ PCR, du VIH-1 chez les enfants nés des mères séropositives. Sci Tech Sci Santé. 2008;31:29-36.

11. Sagna T, Bisseye C, Kagone T, et al. PMTCT of HIV-1 in Burkina Faso: evaluation of residual vertical transmission by PCR, molecular characterization of subtypes and determination of antiretroviral drugs resistance. BMC Infect Dis. 2014;14:P59. doi:10.1186/1471-2334-14-S2-P59

12. Nadembega WM, Giannella S, Simpore J, et al. Characterization of drug-resistance mutations in HIV-1 isolates from non-HAART and HAART treated patients in Burkina Faso. J Med Virol. 2006;78:13851391. doi:10.1002/jmv.20709

13. Autino B, Odolini S, Nitiema H, et al. Prise en charge du VIH/sida et migrations internationales dans le district rural de Nanoro, Burkina Faso [HIV/AIDS and international migration in the rural district of Nanoro, Burkina Faso]. Bull Soc Pathol Exot. 2012;105(2):130-136

14. Sourabie Y, Ouedraogo SM, Bazie WW, et al. Impact of Art Mother and Child on The HIV Status of the Child Born to HIV-Positive Mothers in Burkina Faso: Towards the Adoption of an Effective Pmtct Policy. J Hematol Thrombo Dis. 2015;3(2):1000198.

15. World Health Organization. Prévention De La Transmission MèreEnfant Du VIH/SIDA Au Burkina Faso: Und Démarche Contractuelle Originale : Étude De Cas. Genève, Suisse: Organisation mondiale de la santé; 2004.
16. Ouedraogo SM, Sourabie Y. Impact of art mother and child on the HIV status of the child born to HIV-positive mothers in Burkina Faso: towards the adoption of an effective Pmtct policy. $J$ Hematol Thromboembolic Dis. 2015;03. [cited 2015 Jul 6]. Available from: http://www.esciencecentral.org/journals/impact-of-art-mother-andchild-on-the-hiv-status-of-the-child-born-to-hivpositivemothers-in-bur kina-faso-towards-the-adoption-of-an-effective-pmtctpolicy-23298790-1000198.php?aid=47704.

17. Desclaux A, Alfieri C. Disclosure of Infant HIV Status: Mothers' Experiences and Health Workers' Interpretations in Burkina Faso. SAHARA J: journal of Social Aspects of HIV/AIDS Research Alliance. 2013;10(Suppl 1):S81-S92.

18. Ilboudo D, Simpore J, Ouermi D, et al. Towards the complete eradication of mother-to-child HIV/HBV coinfection at Saint Camille Medical Centre in Burkina Faso, Africa. Braz J Infect Dis Off Publ Braz Soc Infect Dis. 2010;14:219-224.

19. Buchanan AM, Dow DE, Massambu CG, et al. Progress in the prevention of mother to child transmission of HIV in three regions of Tanzania: a retrospective analysis. Harrigan PR, editor. PLoS ONE. 2014;9:e88679. doi:10.1371/journal.pone.0088679

20. Somé JF, Desclaux A, Ky-Zerbo O, et al. Campaigns for HIV testing, an effective strategy for universal access to prevention and treatment? The experience of Burkina Faso. Médecine Santé Trop. 2014;1:7379. doi:10.1684/mst.2014.0298

21. Sartorius BK, Chersich MF, Mwaura M, et al. Maternal anaemia and duration of zidovudine in antiretroviral regimens for preventing motherto-child transmission: a randomized trial in three African countries. BMC Infect Dis. 2013;13:522. doi:10.1186/1471-2334-13-522

22. WHO. Use of antiretroviral drugs for treating pregnant women and preventing HIV infection in infants. Geneva, Switzerland: WHO; 2012:8. Report No.: WHO/HIV/2012.6. Available from: http://www.who.int/hiv/ pub/mtct/programmatic_update2012/en/. Accessed November 10, 2018.

23. Okafor I, Ugwu E, Obi S, Odugu B. Virtual elimination of mother-to-child transmission of human immunodeficiency virus in mothers on highly active antiretroviral therapy in Enugu, South-Eastern Nigeria. Ann Med Health Sci Res. 2014;4:615. doi:10.4103/2141-9248.139344

24. Pignatelli S, Simpore J, Pietra V, et al. Factors predicting uptake of voluntary counselling and testing in a real-life setting in a motherand-child center in Ouagadougou, Burkina Faso. Trop Med Int Health. 2006;11:350-357. doi:10.1111/j.1365-3156.2006.01564.x

25. Barron P, Pillay Y, Doherty T, et al. Eliminating mother-to-child hiv transmission in South Africa. Bull World Health Organ. 2013;91:7074. doi:10.2471/BLT.12.106807

26. Chi BH, Musonda P, Lembalemba MK, et al. Universal combination antiretroviral regimens to prevent mother-to-child transmission of HIV in rural Zambia: a two-round cross-sectional study. Bull World Health Organ. 2014;92:582-592. doi:10.2471/BLT.13.126128

27. Günthard HF, Aberg JA, Eron JJ, et al. Antiretroviral treatment of adult HIV Infection: 2014 recommendations of the International Antiviral Society-USA panel. JAMA. 2014;312:410. doi:10.1001/jama.2014.8722

28. Kendall T, Thorne C. Consequences of missed opportunities for HIV testing during pregnancy and delayed diagnosis for Mexican women, children and male partners. PLoS ONE. Thorne C, editor. 2014;9: e109912. doi:10.1371/journal.pone.0109912.

29. Koye DN, Zeleke BM. Mother-to-child transmission of HIV and its predictors among HIV-exposed infants at a PMTCT clinic in northwest Ethiopia. BMC Public Health. 2013;13:398. doi:10.1186/14712458-13-398

30. Ladner J, Besson M-H, Rodrigues M, Saba J, Audureau E. Performance of HIV prevention of mother-to-child transmission programs in Sub-Saharan Africa: longitudinal assessment of 64 nevirapine-based programs implemented in 25 countries, 20002011. Plos One. Chung MH, editor. 2015;10: 0130103. doi:10.1371/journal.pone.0130103. 
31. Ciaranello AL, Perez F, Engelsmann B, et al. Cost-effectiveness of World Health Organization 2010 guidelines for prevention of motherto-child HIV transmission in Zimbabwe. Clin Infect Dis. 2013;56:430-446. doi:10.1093/cid/cis858

32. Gamell A, Letang E, Jullu B, et al. Uptake of guidelines on prevention of mother-to-child transmission of HIV in rural Tanzania: time for change. Swiss Med Wkly. 2013. doi:10.4414/smw.2013.13775

33. Larsson EC, Ekström AM, Pariyo G, et al. Prevention of mother-tochild transmission of HIV in rural Uganda: modelling effectiveness and impact of scaling-up PMTCT services. Glob Health Action. 2015;8. doi:10.3402/gha.v8.29034.

34. Benn P, Sultan B, Waters L. Current perspectives in HIV post-exposure prophylaxis. HIVAIDS - Res Palliat Care. 2014;6:147-158.

35. Cambiano V, O'Connor J, Phillips A, et al. Antiretroviral therapy for prevention of HIV transmission: implications for Europe. Eurosurveillance. 2013;18:20647. doi:10.2807/1560-7917. ES2013.18.48.20647

36. Khanna AS, Roberts ST, Cassels S, et al. Estimating PMTCT's impact on heterosexual HIV transmission: a mathematical modeling analysis. Moodley D, editor. Plos One. 2015;10:e134271. doi:10.1371/journal. pone. 0134271

37. Busza J, Walker D, Hairston A, et al. Community-based approaches for prevention of mother to child transmission in resource-poor settings: a social ecological review. J Int AIDS Soc. 2012;15. doi:10.7448/IAS.15.4.17373.

38. Kalembo FW, Yukai D, Zgambo M, Jun Q. Male partner involvement in prevention of mother to child transmission of HIV in Sub-Saharan Africa: successes, challenges and way forward. Open J Prev Med. 2012;02:35-42. doi:10.4236/ojpm.2012.21006

39. Mofenson LM. Prevention in neglected subpopulations: prevention of mother-to-child transmission of HIV infection. Clin Infect Dis. 2010;50:S130-48. doi:10.1086/651484

40. Minniear TD, Girde S, Angira F, et al. Outcomes in a cohort of women who discontinued maternal triple-antiretroviral regimens initially used to prevent mother-to-child transmission during pregnancy and breastfeeding-Kenya, 2003-2009. Newell M-L, editor. PLoS ONE. 2014;9:e93556. doi:10.1371/journal.pone.0093556

41. Bucagu M, Muganda J. Implementing primary health care-based PMTCT interventions: operational perspectives from Muhima cohort analysis (Rwanda). Pan Afr Med J. 2014;18. doi:10.11604/ pamj.2014.18.226.4800

42. Schwartz SR, Papworth E, Ky-Zerbo O, et al. Safer conception needs for HIV prevention among female sex workers in Burkina Faso and Togo. Infect Dis Obstet Gynecol. 2014;2014:1-9. doi:10.1155/2014/296245

43. Chi BH, Bolton-Moore C, Holmes CB. Prevention of mother-to-child HIV transmission within the continuum of maternal, newborn, and child health services. Curr Opin HIV AIDS. 2013;8:497-502. doi:10.1097/COH.0b013e3283637f7a

44. Salam RA, Mansoor T, Mallick D, Lassi ZS, Das JK, Bhutta ZA. Essential childbirth and postnatal interventions for improved maternal and neonatal health. Reprod Health. 2014;11:S3. doi:10.1186/1742-4755-11-89

45. Sripan P, Le Coeur S, Amzal B, et al. Modeling of in-utero and intrapartum transmissions to evaluate the efficacy of interventions for the prevention of perinatal HIV. Chung MH, editor. Plos One. 2015;10: e0126647. doi:10.1371/journal.pone.0126647

46. Montoya-Ferrer A, Zorrilla AM, Viljoen J, et al. High level of HBV DNA virus in the breast milk seems not to contraindicate breastfeeding. Mediterr J Hematol Infect Dis. 2015;7:e2015042. doi:10.4084/mjhid.2015.042

47. de Vincenzi I. Kesho Bora tudy Group. Triple antiretroviral compared with zidovudine and single-dose nevirapine prophylaxis during pregnancy and breastfeeding for prevention of mother-to-child transmission of HIV-1 (Kesho Bora study): a randomised controlled trial. Lancet Infect Dis. 2011;11:171-180. doi:10.1016/S1473-3099(10)70288-7
48. Cournil A, Van de Perre P, Cames C, et al. Early infant feeding patterns and HIV-free SURVIVAL: findings from the Kesho-Bora Trial (Burkina Faso, Kenya, South Africa). Pediatr Infect Dis J. 2015;34:168-174. doi:10.1097/INF.0000000000000512

49. WHO. Antiretroviral drugs for treating pregnant women and preventing HIV infection in infants in resource-limited settings: towards universal access. Recommendations for public health approach 2006 [Internet]. WHO; 2006. Available from: http://www.who.int/hiv/pub/ guidelines/pmtct/en/index.html. Accessed October 31, 2018.

50. Thomas TK, Masaba R, Borkowf CB, et al. Triple-antiretroviral prophylaxis to prevent mother-to-child HIV transmission through breastfeeding - the Kisumu breastfeeding study, Kenya: a clinical trial. Mofenson L, editor. PLoS Med. 2011;8:e1001015. doi:10.1371/journal.pmed.1001015

51. Nacro B, Barro M, Gaudreault S, Dao B. Prevention of mother to child transmission of HIV in Burkina Faso: breastfeeding and wet nursing. J Trop Pediatr. 2010;56:183-186. doi:10.1093/tropej/ fmp083

52. Sarker M, Sanou A, Snow R, Ganame J, Gondos A. Determinants of HIV counselling and testing participation in a prevention of motherto-child transmission programme in rural Burkina Faso: determinants of HIV counselling. Trop Med Int Health. 2007;12:1475-1483. doi:10.1111/j.1365-3156.2007.01956.x

53. OuédraogoYugbaré SO, Zagré N, Koueta F, et al. Effectiveness of prevention of mother to child transmission of human immunodeficiency virus by the 2010 protocol of the World Health Organisation at the Medical Center St. Camille of Ouagadougou (Burkina Faso). Pan Afr Med J. 2015;22:303.

54. WHO. Consolidated Guidelines on the Use of Antiretroviral Drugs for Treating and Preventing HIV Infection. Geneva, Switzerland: WHO;2013.

55. Schlossberg D. Clinical Infectious Disease. Second. University of Cambridge: Cambridge University Press; 2015. [cited 2017 Apr 28]. Available from www.cambridge.org/987110738912.

56. SEP/CNLS. Normes et protocoles de prise en charge médicale des personnes vivant avec le VIH au Burkina Faso [Internet]. Burkina Faso: CNLS; 2014. Available from: http://www.remed.org/recomman dations_officielles_du_ministere_de_la_sante_nov2008.pdf. Accessed October 30, 2018.

57. Soubeiga TS, Bisseye C, Compaore R, et al. Effectiveness of the prevention of mother-to-child transmission of HIV protocol applied at Saint Camille Medical Centre in Ouagadougou, Burkina Faso. J Int AIDS Soc. 2014;17. [cited 2015 Jul 6]. Available from http://www. jiasociety.org/index.php/jias/article/view/19701.

58. Chaillon A, Samleerat T, Zoveda F, et al. Estimating the timing of mother-to-child transmission of the human immunodeficiency virus type 1 using a viral molecular evolution model. Vartanian J-P, editor. PLoS ONE. 2014;9:e90421. doi:10.1371/journal.pone. 0090421

59. Lihana RW, Ssemwanga D, Abimiku A, Ndembi N. Update on HIV-1 diversity in Africa: a decade in review. AIDS Rev. 2012;14:83-100.

60. Lau KA, Wong JJL. Current trends of HIV recombination worldwide. Infect Dis Rep. 2013;5:4. doi:10.4081/idr.2013.s1.e4

61. Santoro MM, Perno CF. HIV-1 genetic variability and clinical implications. ISRN Microbiol. 2013;2013:1-20. doi:10.1155/2013/596429

62. Tiwari RP, Jain A, Khan Z, Kumar P, Bhrigu V, Bisen PS. Designing of novel antigenic peptide cocktail for the detection of antibodies to HIV-1/2 by ELISA. J Immunol Methods. 2013;387:157-166. doi:10.1016/j.jim.2012.10.009

63. Eriksson EM, Liegler T, Keh CE, et al. Newly exerted t cell pressures on mutated epitopes following transmission help maintain consensus HIV-1 sequences. Paxton WA, editor. Plos One. 2015;10:e120787. doi:10.1371/journal.pone.0120787 
64. Gijsbers EF, van Nuenen AC, de la Peňa AT, et al. Low level of HIV-1 evolution after transmission from mother to child. Sci Rep. 2014;4. [cited 2015 Jul 29]. Available from http://www.nature.com/doifinder/10.1038/ srep05079.

65. Adelekan AL, Edoni ER, Olaleye OS. Married men perceptions and barriers to participation in the prevention of mother-to-child HIV transmission care in Osogbo, Nigeria. $J$ Sex Transm Dis. 2014;2014:1-6. doi:10.1155/2014/680962

66. Kalembo FW, Zgambo M, Mulaga AN, Yukai D, Ahmed NI. Association between male partner involvement and the uptake of prevention of motherto-child transmission of HIV (PMTCT) interventions in Mwanza District, Malawi: a retrospective cohort study. PLOS ONE. Kissinger P, editor. 2013;8:e66517. doi:10.1371/journal.pone.0066517.

67. Morfaw F, Mbuagbaw L, Thabane L, et al. Male involvement in prevention programs of mother to child transmission of HIV: a systematic review to identify barriers and facilitators. Syst Rev. 2013;2:5. doi:10.1186/2046-4053-2-5

68. Nyondo A, Chimwaza A, Muula A. Stakeholders' perceptions on factors influencing male involvement in prevention of mother to child transmission of HIV services in Blantyre, Malawi. BMC Public Health. 2014;14:691. doi:10.1186/1471-2458-14-691

69. Nyondo AL, Muula AS, Chimwaza AF. Assessment of strategies for male involvement in the prevention of mother-to-child transmission of HIV services in Blantyre, Malawi. Glob Health Action. 2013;6:22780. doi:10.3402/gha.v6i0.22780

70. Pulerwitz J, Michaelis A, Verma R, Weiss E. Addressing gender dynamics and engaging men in HIV programs: lessons learned from horizons research. Public Health Rep. 2010;125:282-292. doi:10.1177/003335491012500514

71. Brittain K, Giddy J, Myer L, Cooper D, Harries J, Stinson K. Pregnant women's experiences of male partner involvement in the context of prevention of mother-to-child transmission in Khayelitsha, South Africa. AIDS Care. 2015;27:1020-1024. doi:10.1080/ 09540121.2015.1018862

72. Shamu S, Zarowsky C, Shefer T, Temmerman M, Abrahams N. Intimate partner violence after disclosure of HIV test results among pregnant women in Harare, Zimbabwe. PLoS ONE. Chung MH, editor. 2014;9:e109447. doi:10.1371/journal.pone.0109447.

73. Haile F, Brhan Y. Male partner involvements in PMTCT: a cross sectional study, Mekelle, Northern Ethiopia. BMC Pregnancy Childbirth. 2014;14:65. doi:10.1186/1471-2393-14-65

74. Kairania R, Gray RH, Kiwanuka N, et al. Disclosure of HIV results among discordant couples in Rakai, Uganda: a facilitated couple counselling approach. AIDS Care. 2010;22:1041-1051. doi:10.1080/ 09540121003602226

75. Tilahun M, Mohamed S. Male partners' involvement in the prevention of mother-to-child transmission of HIV and associated factors in Arba Minch Town and Arba Minch Zuria Woreda, Southern Ethiopia. Biomed Res Int. 2015;2015:1-6. doi:10.1155/2015/763876

76. Sherr L, Croome N. Involving fathers in prevention of mother to child transmission initiatives - what the evidence suggests. $J$ Int AIDS Soc. 2012;15. doi:10.7448/IAS.15.4.17378

77. Auvinen J, Kylma J, Valimaki M, Bweupe M, Suominen T. LubaKasai Men and the prevention of mother to child transmission (PMTCT) of HIV program in Lusaka. Health Promot Int. 2014. [cited 2015 Aug 16]. Available from http://www.heapro.oxfordjour nals.org/cgi/doi/10.1093/heapro/dat088.
78. Sarker M, Papy J, Traore S, Neuhann F. Insights on HIV pre-test counseling following scaling-up of PMTCT program in rural health posts, Burkina Faso. East Afr J Public Health. 2009;6:280-286.

79. Hardon A, Gomez GB, Vernooij E, et al. Do support groups members disclose less to their partners? The dynamics of HIV disclosure in four African countries. BMC Public Health. 2013;13:589. doi:10.1186/1471-2458-13-589

80. De Allegri M, Agier I, Tiendrebeogo J, et al. Factors affecting the uptake of HIV testing among men: a mixed-methods study in rural Burkina Faso. Thielman NM, editor. Plos One. 2015;10:e130216. doi:10.1371/journal.pone.0130216

81. Obermeyer CM, Sankara A, Bastien V, Parsons M. Gender and HIV testing in Burkina Faso: an exploratory study. Soc Sci Med. 2009;69:877-884. doi:10.1016/j.socscimed.2009.07.003

82. Ramirez-Ferrero E, Lusti-Narasimhan M. The role of men as partners and fathers in the prevention of mother-to-child transmission of HIV and in the promotion of sexual and reproductive health. Reprod Health Matters. 2012;20:103-109. doi:10.1016/S0968-8080(12)39642-0

83. Theuring S, Mbezi P, Luvanda H, Jordan-Harder B, Kunz A, Harms G. Male involvement in PMTCT services in Mbeya Region, Tanzania. AIDS Behav. 2009;13:92-102. doi:10.1007/s10461-009-9543-0

84. Drake AL, Wilson SK, Kinuthia J, et al. Health care-seeking behaviour of HIV-infected mothers and male partners in Nairobi, Kenya. Glob Public Health. 2015;10(10):1215-1226. doi:10.1080/ 17441692.2014.1003573

85. Jones D, Peltzer K, Weiss SM, et al. Implementing comprehensive prevention of mother-to-child transmission and HIV prevention for South African couples: study protocol for a randomized controlled trial. Trials. 2014;15:417. doi:10.1186/1745-6215-15-417

86. McMahon JM, Tortu S, Pouget ER, Torres L, Rodriguez W, Hamid R. Effectiveness of couple-based HIV counseling and testing for women substance users and their primary male partners: a randomized trial. Adv Prev Med. 2013;2013:1-15. doi:10.1155/2013/286207

87. WHO. Department of HIV/AIDS. Guidance on Couples HIV Testing and Counselling Including Antiretroviral Therapy for Treatment and Prevention in Serodiscordant Couples: Recommendations for a Public Health Approach. Geneva, Switzerland: World Health Organization; 2012.

88. Ezeanolue EE, Obiefune MC, Yang W, Obaro SK, Ezeanolue CO, Ogedegbe GG. Comparative effectiveness of congregation- versus clinic-based approach to prevention of mother-to-child HIV transmission: study protocol for a cluster randomized controlled trial. Implement Sci. 2013;8:62. doi:10.1186/1748-5908-8-62

89. Kohler PK, Okanda J, Kinuthia J, et al. Community-based evaluation of PMTCT uptake in Nyanza Province, Kenya. Thorne C, editor. PLoS ONE. 2014;9:e110110. doi:10.1371/journal.pone.0110110

90. Spangler SA, Onono M, Bukusi EA, Cohen CR, Turan JM. HIVpositive status disclosure and use of essential PMTCT and maternal health services in Rural Kenya. JAIDS J Acquir Immune Defic Syndr: 2014;67:S235-42. doi:10.1097/QAI.0000000000000294.

91. Some E, Meda N. Does the national program of prevention of mother to child transmission of HIV (PMTCT) reach its target in Ouagadougou, Burkina Faso. Afr Health Sci. 2015;14:889-898. doi:10.1097/QAI.0000000000000294. 


\section{Publish your work in this journal}

HIV/AIDS - Research and Palliative Care is an international, peerreviewed open-access journal focusing on advances in research in HIV, its clinical progression and management options including antiviral treatment, palliative care and public healthcare policies to control viral spread. The manuscript management system is completely online and includes a very quick and fair peer-review system, which is all easy to use. Visit http://www.dovepress.com/testimonials.php to read real quotes from published authors.

Submit your manuscript here: https://www.dovepress.com/hivaids—research-and-palliative-care-journal 